\title{
Studies on Li3AIF6 thin film deposition utilizing conversion reactions of thin films
}

\section{Mäntymäki, Miia Johanna}

2017

Mäntymäki , M J , Mizohata , K , Heikkilä , M J , Räisänen , J A , Ritala , M K \& Leskelä , M A 2017 , ' Studies on Li3AIF6 thin film deposition utilizing conversion reactions of thin films ' , Thin Solid Films , vol. 636 , pp. 26-33 . https://doi.org/10.1016/j.tsf.2017.05.026

http://hdl.handle.net/10138/310946

https://doi.org/10.1016/j.tsf.2017.05.026

cc_by_nc_nd

acceptedVersion

Downloaded from Helda, University of Helsinki institutional repository.

This is an electronic reprint of the original article.

This reprint may differ from the original in pagination and typographic detail.

Please cite the original version. 


\title{
Studies on $\mathrm{Li}_{3} \mathrm{AlF}_{6}$ Thin Film Deposition Utilizing Conversion Reactions of Thin Films
}

Miia Mäntymäki*a ${ }^{\mathrm{a}}$, Kenichiro Mizohata ${ }^{\mathrm{b}}$, Mikko J. Heikkiläa ${ }^{\mathrm{a}}$ Jyrki Räisänen ${ }^{\mathrm{b}}$, Mikko Ritala ${ }^{\mathrm{a}}$, and Markku Leskelä ${ }^{\mathrm{a}}$

${ }^{a}$ Department of Chemistry, University of Helsinki, P.O. Box 55, FI-00014 Helsinki, Finland

${ }^{\mathrm{b}}$ Department of Physics, University of Helsinki, P.O. Box 43, FI-00014 Helsinki, Finland

* corresponding author, miia.mantymaki@helsinki.fi , tel. +358504485721

\begin{abstract}
The ternary lithium aluminum fluoride $\mathrm{Li}_{3} \mathrm{AlF}_{6}$ is formed from two optically interesting fluorides, $\mathrm{LiF}$ and $\mathrm{AlF}_{3}$. It has been reported to have a large electronic bandgap with a reasonable lithium-ion conductivity at room temperature, making it a potential electrolyte material for solid-state lithium-ion batteries. Because of complications during attempts at direct atomic layer deposition of $\mathrm{Li}_{3} \mathrm{AlF}_{6}$, we have studied the deposition of the material using two conversion processes. In Process 1, a conversion reaction takes place when $\mathrm{Al}(\text { thd })_{3}$ and $\mathrm{TiF}_{4}$ are sequentially pulsed onto $\mathrm{LiF}$ films. The films contained $\mathrm{LiF}$ as an impurity phase, as determined with grazing incidence X-ray diffraction (GIXRD), and a large amount of titanium impurity, as determined with time-of-flight elastic recoil detection analysis (ToFERDA). In Process 2, $\mathrm{AlF}_{3}$ films are exposed to Lithd vapor, resulting in a conversion reaction that produced $\mathrm{Li}_{3} \mathrm{AlF}_{6}$ with some LiF. These films have also been studied with GIXRD and ToF-ERDA, and contained much smaller amounts of titanium and other impurities. The Li:Al metal ratios vary depending on the extent of Lithd exposure. Field emission scanning electron microscopy (FESEM) revealed that the $\mathrm{Li}_{3} \mathrm{AlF}_{6}$ films are quite porous.
\end{abstract}

Keywords: thin films, fluoride thin films, conversion reaction, lithium aluminum fluoride 


\section{Introduction}

$\mathrm{Li}_{3} \mathrm{AlF}_{6}$ is composed of two optically interesting fluorides, $\mathrm{LiF}$ and $\mathrm{AlF}_{3}$. This material is best known for having many crystalline phases [1-7], and for being a good solid lithium-ion conductor. The material has been reported to have conductivities of the order of $10^{-6} \mathrm{~S} / \mathrm{cm}$ both in the amorphous (usually written in the form of the non-equilibrium compound $\mathrm{LiAlF}_{4}$ ) [8-10] and crystalline form $[11,12]$, which makes it competitive with more traditional solid state lithium ion battery electrolyte materials such as LiPON $\left(10^{-7} \mathrm{~S} / \mathrm{cm}\right)[13,14]$ and $\mathrm{LiTaO}_{3}\left(10^{-8} \mathrm{~S} / \mathrm{cm}\right)[15]$. As a compound of two fluorides it is no surprise that the material also has a large bandgap of $\sim 12.5 \mathrm{eV} \mathrm{[16],} \mathrm{which} \mathrm{further}$ increases its potential as a solid electrolyte material for all-solid-state lithium-ion batteries.

$\mathrm{Li}_{3} \mathrm{AlF}_{6}$ can be deposited by various methods, including the sol-gel method [17] and thermal evaporation [10]. To be applicable in all-solid-state lithium-ion batteries, a material must be deposited using a method which provides, among other things, good film quality and thickness control. Atomic layer deposition (ALD) is a thin film deposition method that can provide these properties. By definition, ALD is based on saturative, self-limiting surface reactions [18], and is usually realized by the sequential pulsing of gaseous precursors onto a substrate, with purging steps applied between the precursor pulses to avoid gas phase reactions. ALD is mostly used in depositing materials such as transition metal oxides for microelectronics and memory devices [19]. Both binary and ternary materials can be deposited using ALD, with the ternary deposition often done by combining binary material subcycles into a supercycle (Scheme 1) [20]. Despite its inherent simplicity, the subcycle approach can prove problematic in some cases, for example due to exchange reactions and differing film growth rates on changing deposition surfaces [21]. 
Scheme 1: An example of ternary material deposition by ALD using the subcycle approach, where the cycles of binary materials are combined in a desired ratio (x subcycles of $\mathrm{TiO}_{2}$ before y subcycles of $\mathrm{BaO}$ ) to deposit the ternary material $\left(\mathrm{BaTiO}_{3}\right)[22]$.

After the first paper on ALD of lithium-containing materials was published in 2009 [23], ALD has gained much interest also in the field of lithium-ion batteries, and many binary and ternary lithium containing materials have already been deposited [24,25]. Despite being a fairly new addition to the periodic table of ALD materials, lithium has already been demonstrated to be able to defy some of the basic rules of ALD with its high reactivity and mobility in ALD conditions [26-28]. For example, lithium has been reported to be able to take part in conversion reactions in ALD conditions [27,28]. While often such conversion reactions can be seen as a complication in the thin film deposition process, with proper process design they can also be used as an advantage. For example, we have studied the conversion of $\mathrm{MgF}_{2}$ thin films into $\mathrm{LiF}$ using a Lithd precursor exposure. We found that the resulting LiF films were very pure and had many advantageous properties compared to LiF deposited with traditional ALD, including better adhesion to the silicon substrate and smaller surface roughness [27]. Recently, a similar vapor-solid conversion reaction has been applied for the deposition of metalorganic frameworks from ALD zinc oxide, further proving that conversion reactions can produce high quality thin films [29].

Metal fluorides have been deposited by ALD since the early 1990s [30]. In the first studies HF, which was generated by decomposing $\mathrm{NH}_{4} \mathrm{~F}$, was used as the fluorine precursor. $\mathrm{HF}$ is still a popular fluorine source today, and both $\mathrm{AlF}_{3}$ and $\mathrm{Li}_{3} \mathrm{AlF}_{6}$ have been deposited using this fluorine precursor $[12,31,32]$. The $\mathrm{Li}_{3} \mathrm{AlF}_{6}$ deposition, reported thus far only in a conference presentation and as a part of a doctoral dissertation, combined HF with metal precursors TMA (trimethylaluminum) and LiHMDS (lithium 
bis(trimethylsilyl)amide, or lithium hexamethyldisilazide) [12]. Due to the hazardous nature of HF, our group has extensively studied the ALD of fluorides using metal fluorides, such as $\mathrm{TiF}_{4}$ and $\mathrm{TaF}_{5}$, as fluorine sources [27,33-39]. These halides can take part in exchange reactions with both metal-thd complexes and chlorides, forming a solid fluoride material and volatile side products of the type $\mathrm{TiF}_{\mathrm{x}}(\text { thd })_{4-\mathrm{x}}$ or $\mathrm{TiF}_{\mathrm{x}} \mathrm{Cl}_{4-\mathrm{x}}$ with only small impurity contents in the films.

In this paper, we report on the deposition of $\mathrm{Li}_{3} \mathrm{AlF}_{6}$ thin films. Our initial experiments on using the ALD subcycle approach were unsuccessful due to the facile conversion of $\mathrm{AlF}_{3}$ to $\mathrm{LiF}$ during the deposition process. Therefore, alternative deposition processes utilizing conversion reactions were developed: First, ALD-made LiF thin films were used as a substrate film for a deposition process utilizing $\mathrm{Al}(\text { thd) })_{3}$ (aluminum tris(2,2,6,6-tetramethyl-3,5-heptanedionate) and $\mathrm{TiF}_{4}$ as precursors (Process 1, Scheme 2). In the second, more successful approach (Process 2, Scheme 3), $\mathrm{AlF}_{3}$ thin films were atomic layer deposited first from $\mathrm{AlCl}_{3}$ and $\mathrm{TiF}_{4}$, and then exposed to the lithium precursor Lithd (lithium 2,2,6,6-tetramethyl-3,5-heptanedionate) in an ALD-reactor. This exposure led to an efficient conversion reaction that resulted in crystalline $\mathrm{Li}_{3} \mathrm{AlF}_{6}$ formation.

Scheme 2: Process 1 utilizes $\mathrm{Al}(\text { thd })_{3}$ and $\mathrm{TiF}_{4}$ in a conversion reaction to form $\mathrm{Li}_{3} \mathrm{AlF}_{6}$ out of $\mathrm{LiF}$ thin films.

Scheme 3: Process 2 uses a conversion reaction between $\mathrm{ALD}$-made $\mathrm{AlF}_{3}$ and the lithium precursor Lithd to deposit $\mathrm{Li}_{3} \mathrm{AlF}_{6}$. 


\section{Experimental details}

\subsection{Film deposition}

All thin film depositions and conversion reactions were conducted using an ASM Microchemistry F120 hot-wall flow-type ALD reactor. The $\mathrm{AlF}_{3}$ and $\mathrm{LiF}$ films used as starting surfaces in Processes 1 and 2 were deposited by ALD as previously described in the literature [38,39]. The films were

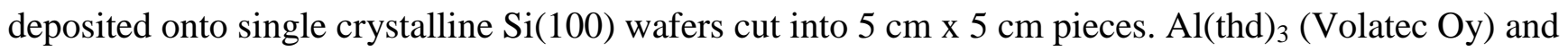
$\mathrm{TiF}_{4}$ (Strem Chemicals Inc., $98 \%$ ) were used as precursors in Process 1 and applied onto LiF films. Lithd (Volatec $\mathrm{Oy}$ ) exposure on $\mathrm{AlF}_{3}$ films was used in Process 2. The pressure inside the reactor was of the order of $5 \mathrm{mbar}(500 \mathrm{~Pa})$ during the experiments. The precursors were evaporated inside the reactor from open glass boats, Lithd at $180{ }^{\circ} \mathrm{C}(453 \mathrm{~K}), \mathrm{Al}(\text { thd })_{3}$ at $113{ }^{\circ} \mathrm{C}(386 \mathrm{~K})$, and $\mathrm{TiF}_{4}$ at $135^{\circ} \mathrm{C}$ (408 K). The pulsing of the precursors was done by inert gas valving. $\mathrm{N}_{2}$ gas, obtained from liquid $\mathrm{N}_{2}$, was used as the carrier and purging gas $\left(\mathrm{H}_{2} \mathrm{O} \leq 3 \mathrm{ppm}, \mathrm{O}_{2} \leq 3 \mathrm{ppm}\right)$.

\subsection{Film characterization}

A Hitachi U2000 spectrophotometer was used to evaluate the thickness and refractive index of the films. The thickness and refractive index values were determined from reflection spectra by a fitting program developed by Ylilammi and Ranta-aho [40]. The wavelength range was 370-1050 nm.

The crystallinity of the films was studied by grazing incidence X-ray diffraction (GIXRD) measurements conducted with a PANalytical X'Pert Pro MPD X-ray diffractometer with parallel beam optics. In situ high temperature XRD (HT-XRD) measurements were conducted in $\mathrm{N}_{2}$ atmosphere, using an Anton-Paar HTK1200N oven. The morphology of the films was studied by field emission scanning electron microscopy (FESEM) with a Hitachi S4800 FESEM instrument. For the FESEM 
imaging, the samples were coated with approximately $2.5 \mathrm{~nm}$ of $\mathrm{Au} / \mathrm{Pd}$ by sputtering using a Cressington 208HR sputter coater.

The composition of the films was studied with time of flight elastic recoil detection analysis (ToFERDA). The ToF-ERDA measurements were performed with $50 \mathrm{MeV}{ }^{127} \mathrm{I}$ and $40 \mathrm{MeV}{ }^{79} \mathrm{Br}$ beams from the 5 MV EGP-10-II tandem accelerator at the University of Helsinki [41]. The detection angle was $40^{\circ}$ and the sample was tilted $16^{\circ}$ relative to the beam direction.

\section{Results and discussion}

\subsection{Process 1}

Process 1 utilized $\mathrm{Al}(\text { thd })_{3}$ and $\mathrm{TiF}_{4}$ for the conversion reaction of $\mathrm{LiF}$ films into $\mathrm{Li}_{3} \mathrm{AlF}_{6}$. Although this precursor combination did not result in $\mathrm{AlF}_{3}$ film growth on silicon or alumina [39], pulsing them onto LiF resulted in a reaction. $\mathrm{Al}(\text { thd })_{3}$ was chosen as the aluminum source, instead of $\mathrm{AlCl}_{3}$ used in our previously reported $\mathrm{AlF}_{3}$ process [39], to avoid the formation of $\mathrm{LiCl}$ as a solid reaction side product upon exposure of $\mathrm{LiF}$ to $\mathrm{AlCl}_{3}$ vapor (Appendix, Figure A.1).

Figure 1 illustrates how the deposition temperature (A), aluminum precursor pulse length (B), and the number of ALD cycles (C) affect the crystallinity of the resulting films. It is evident from the diffractograms that the $\mathrm{LiF}$ film is reacting with the precursors, as the ternary $\mathrm{Li}_{3} \mathrm{AlF}_{6}$ film is forming during the deposition process instead of a separate $\mathrm{AlF}_{3}$ film on $\mathrm{LiF}$. The efficient mixing of the fluorides during the deposition process is not surprising, as both $\mathrm{LiF}$ and $\mathrm{Li}_{3} \mathrm{AlF}_{6}$ are known to be quite good lithium-ion conductors at high temperatures $[42,43]$. Because longer $\mathrm{Al}(\mathrm{thd})_{3}$ pulse times led to more prominent $\mathrm{Li}_{3} \mathrm{AlF}_{6}$ reflections in the X-ray diffractogram (Figure 1B), it is evident that the film 
growth is not self-limiting as in conventional ALD, but rather a continuous conversion reaction is taking place. Based solely on the XRD results of Figure 1, it can be concluded that a large number of deposition cycles, with long $\mathrm{Al}(\text { thd })_{3}$ pulse times and high temperatures, result in $\mathrm{Li}_{3} \mathrm{AlF}_{6}$ films with the smallest amount of crystalline $\mathrm{LiF}$, which in this case is deemed as an impurity phase. However, based on a visual examination of film quality and uniformity, these same parameters result in both poor adhesion, flaky deposits, and overall nonuniform films (Figure 2). Therefore, intermediate temperatures with short precursor pulse times and relatively small cycle numbers were used in the further experiments (Figure 1D).

Figure 1: X-ray diffractograms of films deposited using $\mathrm{Al}(\text { thd })_{3}$ and $\mathrm{TiF}_{4}$ onto $\mathrm{LiF}$ a) at 250,300 and $350{ }^{\circ} \mathrm{C}(523,573$ and $623 \mathrm{~K})$, b) with different $\mathrm{Al}(\text { thd) })_{3}$ pulse lengths, c) with different numbers of cycles at 250 and $300{ }^{\circ} \mathrm{C}(523$ and $573 \mathrm{~K})$ and d) using optimized parameters of $300{ }^{\circ} \mathrm{C}(573 \mathrm{~K})$, small number of cycles and a short $\mathrm{Al}(\text { thd })_{3}$ pulse. Solid lines denote monoclinic $\mathrm{Li}_{3} \mathrm{AlF}_{6}$ and the dashed lines indicate peaks belonging to cubic $\mathrm{LiF}$.

Figure 2: $\mathrm{Li}_{3} \mathrm{AlF}_{6}$ films deposited at 250 (left) and $350{ }^{\circ} \mathrm{C}$ (right) $(523$ and $623 \mathrm{~K}$ ) onto $\mathrm{LiF}$ with 1000 cycles and using a 2 $\mathrm{s} \mathrm{Al}(\text { thd })_{3}$ pulse. Despite a smaller amount of LiF impurity in the X-ray diffractogram, the sample deposited at the higher temperature is otherwise of much lower quality, with flaky deposits and poor adhesion.

Establishing the exact phase of $\mathrm{Li}_{3} \mathrm{AlF}_{6}$ in our samples is challenging since the peak intensities are small and the peaks are broad. $\mathrm{Li}_{3} \mathrm{AlF}_{6}$ is known to show two polymorphs at room temperature [1], namely the orthorhombic $\alpha-\mathrm{Li}_{3} \mathrm{AlF}_{6}[5,44]$ and the monoclinic $\beta-\mathrm{Li}_{3} \mathrm{AlF}_{6}[7,45]$. The peak positions of the most intense peaks of these two polymorphs are very close, making the distinguishing of the phases challenging. It has been reported that the $\alpha$ phase is in fact metastable and forms only after fast quenching from a melt. On the other hand, slow cooling of a melt leads to the monoclinic $\beta$-phase. Based on our analyses, all the $\mathrm{Li}_{3} \mathrm{AlF}_{6}$ films deposited using $\mathrm{Al}(\text { thd })_{3}$ and $\mathrm{TiF}_{4}$ are of the monoclinic 
phase [45]. In addition to the peaks belonging to $\mathrm{Li}_{3} \mathrm{AlF}_{6}$, a shoulder peak residing at $2 \theta=20.6^{\circ}$ appears in Figure 1D. The origin of this peak could not be identified. For the low-quality film deposited at $350{ }^{\circ} \mathrm{C}(623 \mathrm{~K})$ (Figure 2), the phase identification was more challenging. Based on our analyses, the film is most likely a distorted monoclinic $\mathrm{Li}_{3} \mathrm{AlF}_{6}$ phase (difference in cell dimensions $+1-+2 \%$ ). Comparing our results to the literature, $\mathrm{Li}_{3} \mathrm{AlF}_{6}$ films deposited by ALD using $\mathrm{HF}$ as the fluorine source were also crystalline, with wide peaks that were assigned to the monoclinic phase [32].

Elastic recoil detection analysis depth profiles showed that the thickness of the LiF film had a large effect on the elemental distribution of the forming ternary fluoride film (Figure 3). $80 \mathrm{~nm} \mathrm{LiF}$ films were enriched with aluminum only to a certain depth, and below that only Li and F were seen. This explains the large $\mathrm{LiF}$ impurity phase seen in Figure 1 . When using a $50 \mathrm{~nm} \mathrm{LiF}$ film, aluminum is uniformly distributed in the whole film. ERDA also revealed that both $\mathrm{Al}(\text { thd })_{3}$ and $\mathrm{TiF}_{4}$ were necessary for the conversion reaction to occur: without $\mathrm{TiF}_{4}$ pulsing, only negligible amounts of aluminum were found in the lithium fluoride film. Still, even in the best samples obtained using both precursors, based on both XRD and visual inspection, the amount of aluminum was very low. After 750 cycles of $\mathrm{Al}(\text { thd })_{3}$ and $\mathrm{TiF}_{4}$ pulsing, the originally $50 \mathrm{~nm} \mathrm{LiF}$ film of Figure 3 had only 6.6 at $\%$ of $\mathrm{Al}$ and a $\mathrm{Li}: \mathrm{Al}$ ratio of $4.2: 1$. In addition, the amount of titanium impurity in the film was 1.9 at $\%$, resulting in an $\mathrm{Al}:$ Ti ratio of $3.5: 1$. It can be concluded that although Process 1 resulted in visually good-looking films with $\mathrm{Li}_{3} \mathrm{AlF}_{6}$ present in the $\mathrm{X}$-ray diffractograms, the amount of aluminum is in all likelihood too low, and the amount of titanium too high, to result in high lithium-ion conductivities. In addition, all the films contain large amounts of crystalline LiF, confirming that the ALD-type conversion reaction was not an effective route to $\mathrm{Li}_{3} \mathrm{AlF}_{6}$ thin films. 
Figure 3: ToF-ERDA depth profiles of films deposited at $300{ }^{\circ} \mathrm{C}(573 \mathrm{~K})$ using 750 cycles of $\mathrm{Al}(\text { thd })_{3}$ and $\mathrm{TiF} 4$ onto $\mathrm{LiF}$ films of a) $80 \mathrm{~nm}$ and b) $50 \mathrm{~nm}$. With the thicker LiF film, aluminum is only found at the surface layers of the film. With the thinner LiF film, aluminum is more evenly dispersed into the fluoride film.

\subsection{Process 2}

In order to incorporate higher aluminum amounts in the films, Process 2 was developed. In this process, $\mathrm{AlF}_{3}$ films were deposited first with $\mathrm{ALD}$, using $\mathrm{AlCl}_{3}$ and $\mathrm{TiF}_{4}$ as precursors [39], and then exposed to the lithium precursor Lithd. In this process, lithium ions do not get exposed to the aluminum precursor, and thus $\mathrm{AlCl}_{3}$ could be used as the aluminum source for the $\mathrm{AlF}_{3}$ deposition. The reasoning behind this conversion reaction was based on our earlier results on using Lithd to convert $\mathrm{MgF}_{2}$ films [27]. It was of our interest to study whether a similar conversion could be possible with other metal fluoride films and whether mixture fluorides such as $\mathrm{Li}_{3} \mathrm{AlF}_{6}$ could form in this manner.

Approximately $100 \mathrm{~nm}$ thick $\mathrm{AlF}_{3}$ films were exposed to Lithd vapor at $250{ }^{\circ} \mathrm{C}(523 \mathrm{~K})$. The exposure was done by supplying $2 \mathrm{~s}$ Lithd pulses onto the $\mathrm{AlF}_{3}$ films in an ALD reactor. Purge times of $4 \mathrm{~s}$ were employed after each Lithd pulse. The aluminum fluoride films were amorphous before the exposure experiments. Figure 4A and 4B illustrate how the number of Lithd pulses affects the crystallinity of the resulting film. With the smallest numbers of pulses, only little $\mathrm{Li}_{3} \mathrm{AlF}_{6}$ is formed due to negligible amounts of $\mathrm{Li}^{+}$ions incorporated into the film. When the number of Lithd pulses is increase up to 100 pulses, monoclinic $\mathrm{Li}_{3} \mathrm{AlF}_{6}$ becomes more pronounced, with some $\mathrm{LiF}$ as an impurity phase. With the number of pulses exceeding 100, the diffractograms show prominent peaks belonging to $\mathrm{LiF}$. In addition to the peaks belonging to $\mathrm{Li}_{3} \mathrm{AlF}_{6}$, the unidentified shoulder peak at $2 \theta=20.6^{\circ}$ appears again in all the $\mathrm{Li}_{3} \mathrm{AlF}_{6}$ containing samples. 
Figure 4: X-ray diffractograms of films formed by pulsing Lithd over amorphous $\mathrm{AlF}_{3}$ thin films. a) $105 \mathrm{~nm}^{\circ} \mathrm{AlF}_{3}$ at $250{ }^{\circ} \mathrm{C}(523 \mathrm{~K})$ with different numbers of Lithd pulses (low), b) $100 \mathrm{~nm}$ of $\mathrm{AlF}_{3}$ at $250{ }^{\circ} \mathrm{C}(523 \mathrm{~K})$ with different numbers of Lithd pulses (high), c) $56 \mathrm{~nm}$ of $\mathrm{AlF}_{3}$ at $250{ }^{\circ} \mathrm{C}(523 \mathrm{~K})$ with different numbers of Lithd pulses, d) $105 \mathrm{~nm}$ of $\mathrm{AlF}_{3}$ at 250, 275 and $300{ }^{\circ} \mathrm{C}(523,548$ and $573 \mathrm{~K})$ with 40 pulses of Lithd. Solid lines denote monoclinic $\mathrm{Li}_{3} \mathrm{AlF}_{6}$ and the dashed lines indicate peaks belonging to cubic $\mathrm{LiF}$.

Two films made by exposing $100 \mathrm{~nm} \mathrm{AlF}_{3}$ films to Lithd were subjected to a high temperature XRD measurement in $\mathrm{N}_{2}$ to determine whether the crystallinity of the films could be improved. In a film exposed to 50 pulses of Lithd at $250{ }^{\circ} \mathrm{C}(523 \mathrm{~K})$, the monoclinic $\mathrm{Li}_{3} \mathrm{AlF}_{6}$ phase disappears above $400{ }^{\circ} \mathrm{C}(673 \mathrm{~K})$, with a reflection belonging to $\mathrm{LiF}$ becoming visible (Figure $\left.5 \mathrm{~A}\right)$. Even before this, a reflection at $2 \theta \approx 25^{\circ}$ is seen, which could be indexed as (110) of hexagonal $\mathrm{AlF}_{3}$. Thus, it appears that during the heating the ternary fluoride is decomposing to its component binary fluorides. At even higher temperatures lithium silicates, mainly $\mathrm{Li}_{2} \mathrm{SiO}_{3}$, begin to form, as $\mathrm{Li}^{+}$is presumably diffusing into the single crystalline silicon substrate. This is seen as the three low-intensity peaks at $675{ }^{\circ} \mathrm{C}(948 \mathrm{~K})$. This diffusion and reaction of lithium has previously been seen in our experiments on forming multicomponent lithium-containing oxides by solid state reactions between ALD-made transition metal oxides and $\mathrm{Li}_{2} \mathrm{CO}_{3}$ [46]. The formation of a silicate indicates that lithium ions are mobile in the fluoride film at least at high temperatures. Interestingly, there were no indications of the formation of the hightemperature $\mathrm{Li}_{3} \mathrm{AlF}_{6}$ phases, even though these have been reported in the literature [1]. In the film exposed to 100 Lithd pulses no new phases emerged, with only $\mathrm{LiF}$ being present even at $500{ }^{\circ} \mathrm{C}$ (773 K) (Figure 5B). This appears to be due to the low aluminum content caused by the larger Lithd exposure.

Figure 5: High-temperature X-ray diffractograms of a) $100 \mathrm{~nm}$ of $\mathrm{AlF}_{3}$ exposed to 50 Lithd pulses at $250{ }^{\circ} \mathrm{C}(523 \mathrm{~K})$ and b) $100 \mathrm{~nm}$ of $\mathrm{AlF}_{3}$ exposed to 100 Lithd pulses at $250{ }^{\circ} \mathrm{C}(523 \mathrm{~K})$. Measurements were done in a $\mathrm{N}_{2}$ atmosphere. Solid lines denote monoclinic $\mathrm{Li}_{3} \mathrm{AlF}_{6}$ and the dashed lines indicate peaks belonging to cubic $\mathrm{LiF}$. The dash-dot line corresponds to hexagonal $\mathrm{AlF}_{3}$. 
The effect of the extent of the Lithd exposure to film thickness was studied with four samples exposed to $40,33,25$ and 10 pulses of Lithd. The originally $105 \mathrm{~nm} \mathrm{AlF}_{3}$ films showed decreased thicknesses after exposure. The larger the exposure, the larger the difference, with the film exposed to 40 pulses having a thickness of approximately $90 \mathrm{~nm}$, as measured with UV-Vis spectophotometry. The more Lithd pulses were employed, the more difficult it was to fit the UV-Vis reflectance spectra. The refractive index of the films was changing as well, although very subtly: a larger number of Lithd pulses resulted in smaller refractive indices. For example, the refractive index changed from 1.38 in $\mathrm{AlF}_{3}$ to 1.34 in $\mathrm{Li}_{3} \mathrm{AlF}_{6}$ after 33 Lithd pulses.

Approximately $100 \mathrm{~nm} \mathrm{AlF}$ films exposed to 40 and 10 pulses of Lithd at $250{ }^{\circ} \mathrm{C}(523 \mathrm{~K})$ were analyzed with ToF-ERDA. While LiF was visible in the X-ray diffractogram of the sample obtained with 40 pulses (Figure 4A), ERDA revealed that the amount of lithium was still somewhat low in the film, as the $\mathrm{Li}: \mathrm{Al}$ ratio was $1.49: 1$. In the sample made with 10 pulses, the $\mathrm{Li}: \mathrm{Al}$ ratio was only 0.18 : 1. The samples showed 0.6 at $\% \mathrm{Ti}$ and 0.3 at $\% \mathrm{Cl}$ impurities, originating from the $\mathrm{AlF}_{3}$ deposition process. The conversion reaction between Lithd and $\mathrm{AlF}_{3}$ to $\mathrm{Li}_{3} \mathrm{AlF}_{6} / \mathrm{LiF}$ is very clean, as illustrated by the low amounts of elements from the thd-ligand, namely $\mathrm{C}(0.1-0.3$ at $\%), \mathrm{O}(1.3$ at $\%)$ and $\mathrm{H}(0.1-$ 0.4 at\%). Similarly low impurity contents were also obtained with the $\mathrm{MgF}_{2}$-to-LiF conversion process [27]. Thus, our films contain as little impurities as $\mathrm{Li}_{3} \mathrm{AlF}_{6}$ films deposited with ALD using HF as the fluorine source [12].

Because of the relatively low amount of lithium in the samples made using approximately $100 \mathrm{~nm} \mathrm{AlF}_{3}$ films, thinner $\mathrm{AlF}_{3}$ films were also exposed to Lithd. As can be seen in Figure $4 \mathrm{C}$, after 40 pulses of Lithd a $56 \mathrm{~nm} \mathrm{AlF}_{3}$ film showed a much larger amount of crystalline LiF formed, as compared to a 100 $\mathrm{nm} \mathrm{AlF}_{3}$ film. Figure 6 shows the ERDA depth profiles of $\mathrm{AlF}_{3}$ films of different thickness exposed to 
40 pulses of Lithd, and corroborates the XRD results in that a much higher lithium content can be found in the thinner $\mathrm{AlF}_{3}$ sample. With 20 and 10 pulses, the X-ray diffraction peaks belonging to $\mathrm{LiF}$ became much less pronounced. ERDA revealed that in samples made with 40 Lithd pulses, the Li : Al ratio varied between $6.6: 1$ and $7.9: 1$, meaning that the films were highly lithium-rich. With 20 pulses of Lithd the metal ratio was only close to $1: 1$. Thus, doubling the Lithd exposure increases the amount of lithium 6-7 fold, indicating that the conversion is very efficient and not limited only to the very surface of the film. As a result, the achieved metal ratio depends not only on the number of Lithd pulses but also on the original $\mathrm{AlF}_{3}$ film thickness.

Figure 6: ToF-ERDA depth profiles of a) $56 \mathrm{~nm}$ and b) $105 \mathrm{~nm} \mathrm{AlF}_{3}$ films exposed to 40 pulses of Lithd at $250{ }^{\circ} \mathrm{C}(523 \mathrm{~K})$.

The effect of the Lithd exposure temperature was also studied. Previously we reported that higher exposure temperatures resulted in faster conversion of $\mathrm{MgF}_{2}$ films into $\mathrm{LiF}$ [27]. In the case of $\mathrm{AlF}_{3}, 40$ Lithd pulses at $300{ }^{\circ} \mathrm{C}(573 \mathrm{~K})$ on an approximately $100 \mathrm{~nm} \mathrm{AlF}_{3}$ film resulted in a noncontinuous film that contained both $\mathrm{LiF}$ and $\mathrm{Li}_{3} \mathrm{AlF}_{6}$ (Figure 4D). At the exposure temperature of $275^{\circ} \mathrm{C}(548 \mathrm{~K})$ the film showed prominent $\mathrm{XRD}$-peaks belonging to $\mathrm{LiF}$, and the film quality was much better than at $300{ }^{\circ} \mathrm{C}(573 \mathrm{~K})$. For a $100 \mathrm{~nm} \mathrm{AlF}_{3}$ film, the conversion at $275^{\circ} \mathrm{C}(548 \mathrm{~K})$ with 40 Lithd pulses produced a film with a Li:Al ratio of $2.1: 1$. This ratio is the closest to the correct stoichiometry of $\mathrm{Li}_{3} \mathrm{AlF}_{6}$ reached in these experiments.

The ERDA measurements revealed the sensitivity of this method to the Lithd exposure conditions. Because the reaction is not restricted to the surface as in ALD processes, the Lithd dose is critically important. The dose depends on the temperature and pressure conditions where the Lithd is evaporated. Because these experiments were conducted using an ALD-reactor, both of these variables could be 
easily monitored, and an effort was made to keep the reactor conditions exactly the same during the experiments. The repeatability of the conversion reaction was reasonably good, with the $\mathrm{Li}: \mathrm{Al}$ ratio varying only slightly in samples converted at different times (Figure 7). Moreover, the relationship between the lithium contents and the number of lithium pulses was close to linear.

Figure 7: The cation percentage of lithium in converted $\mathrm{AlF}_{3}$ films at different temperatures as a function of the number of Lithd exposure pulses. Black and white symbols denote samples prepared at different times but with using same parameters for exposure. The solid line denotes the desired stoichiometry found in $\mathrm{Li}_{3} \mathrm{AlF}_{6}$.

It can be concluded from the XRD and ERDA results that to achieve high lithium contents, it is better to expose thinner $\mathrm{AlF}_{3}$ films to Lithd. However, for easier controllability of the deposition process, thicker films are preferred. Higher exposure temperatures should lead to somewhat faster conversion, but can also pose problems related to film uniformity, similarly as was observed also for Process 1 . An interesting aspect of these results is that although the lithium content of the films was mostly much smaller than desired for the stoichiometric $\mathrm{Li}_{3} \mathrm{AlF}_{6}$, the X-ray diffractograms regularly showed prominent peaks belonging to crystalline LiF. It seems that the crystallization of LiF is somewhat preferential to the formation of $\mathrm{Li}_{3} \mathrm{AlF}_{6}$ in our exposure conditions.

It is interesting to compare our results on conversion reactions to the ALD of $\mathrm{Li}_{3} \mathrm{AlF}_{6}$ using $\mathrm{TMA}$, LiHMDS and HF [12]. In these experiments the subcycle approach for ternary fluoride deposition was used, and it was reported that using one subcycle of $\mathrm{AlF}_{3}$ and one subcycle of $\mathrm{LiF}$ resulted in the deposition of a mixed fluoride with a $\mathrm{Li}: \mathrm{Al}$ ratio of $2.7: 1$, as determined with ICP-MS. No mention was made on conversion reactions similar to what we report here. Still, it was noted that no change in the metal stoichiometry was achieved even if three $\mathrm{AlF}_{3}$ subcycles were used with one $\mathrm{LiF}$ subcycle. This may indicate that some conversion type reactions were taking place also in that deposition 
process. The depositions were done at $150{ }^{\circ} \mathrm{C}(423 \mathrm{~K})$, which is much lower than the temperatures used in our experiments. At this low temperature conversion reactions are most likely very slow, making them difficult to notice especially when the effect of different $\mathrm{LiF}: \mathrm{AlF}_{3}$ pulsing ratios were not studied extensively.

FESEM imaging was used to compare the surface morphology of the films exposed to 10 and 40 pulses of Lithd at $250{ }^{\circ} \mathrm{C}(523 \mathrm{~K})$. The $\mathrm{AlF}_{3}$ films are amorphous and therefore have featureless surfaces before the exposure experiments [39]. After 10 Lithd pulses, both the $100 \mathrm{~nm}$ and $50 \mathrm{~nm} \mathrm{AlF}$ films showed very small particulates formed on the otherwise relatively smooth surface (Figure 8). In both samples some void formation is evident at higher magnification, with the voids being larger in the 100 $\mathrm{nm}$ sample. These might be due to changes in the film volume caused by the conversion reactions. Such a void formation was not observed in our previous study where $\mathrm{MgF}_{2}$ films were converted to $\mathrm{LiF}$ [27].

Figure 8: FESEM images of $\mathrm{AlF}_{3}$ films exposed to Lithd at $250{ }^{\circ} \mathrm{C}(523 \mathrm{~K})$. For $\left.\mathrm{A}\right)$ and $\left.\mathrm{B}\right)$, films were exposed to 10 pulses. For C) and D), 40 pulses were used. Magnification is 100k for large images and 25k for the insets.

The film morphology changes drastically when 40 pulses of Lithd are employed (Figure 8C and 8D). Despite the large difference in the $\mathrm{Li}: \mathrm{Al}$ ratios, as discussed earlier, the film structure is similar in both the $100 \mathrm{~nm}$ and $50 \mathrm{~nm}$ samples. The films are clearly crystalline with small grains forming a porous surface. Interestingly, even though the $50 \mathrm{~nm}$ sample showed strong diffraction peaks belonging to $\mathrm{LiF}$ and a large Li excess in ERDA, the film morphology does not resemble that of the cubic lithium fluoride deposited by ALD or by conversion reactions from $\mathrm{MgF}_{2}$ [27,38]. This porous morphology can explain the decrease in the refractive indices of the films exposed to larger amounts of Lithd. Because of the morphology, attempts at depositing $\mathrm{Pt}_{-} \mathrm{Li}_{3} \mathrm{AlF}_{6}-\mathrm{Pt}$ structures for electrical characterization failed; 
the evaporated Pt top electrode seemed to short circuit to the bottom electrode. Further research is required to either better control the morphology of the films, or seal the porosity with a proper top layer.

\section{Conclusion}

We have studied the thin film deposition of $\mathrm{Li}_{3} \mathrm{AlF}_{6}$ using two processes. The ALD-type conversion reaction of $\mathrm{LiF}$ films using alternative pulsing of $\mathrm{Al}(\mathrm{thd})_{3}$ and $\mathrm{TiF}_{4}$ resulted in low aluminum contents and large amounts of impurities in the $\mathrm{Li}_{3} \mathrm{AlF}_{6}$ films. By reacting $\mathrm{AlF}_{3}$ films with Lithd vapor we were able to obtain films with a $\mathrm{Li}: \mathrm{Al}$ ratio of $2.1: 1$. The films deposited with the conversion reaction were quite porous, as determined with FESEM imaging, and contained some LiF as an impurity phase, based on XRD measurements.

In this study it was found that the tendency of $\mathrm{Li}^{+}$to take part in conversion reactions during deposition processes, and the high stability of crystalline LiF, result in mixture fluoride films which are lithiumdeficient compared to the desired $\mathrm{Li}_{3} \mathrm{AlF}_{6}$, and yet contain crystalline $\mathrm{LiF}$ as an impurity phase. For future work, it would seem that depositing $\mathrm{Li}_{3} \mathrm{AlF}_{6}$ requires a method which does not allow $\mathrm{Li}^{+}$to reach equilibrium. As already mentioned, thermal evaporation and fast quenching has been reported to form $\mathrm{Li}_{3} \mathrm{AlF}_{6}[8,10]$. More work should be put into studying the conversion reactions of $\mathrm{Li}^{+}$with methods such as EXAFS, which give information on the local structure around a particular atom. 


\section{Appendix}

Figure A.1: Gibbs free energy for the reaction of $\mathrm{LiF}$ with $\mathrm{AlCl}_{3}$ as a function of temperature. The Gibbs free energy values were calculated with HSC Chemistry 5.11 software.

\section{Acknowledgements}

Financial support from ASM Microchemistry oy is gratefully acknowledged. This work was also supported by the Finnish Centre of Excellence in Atomic Layer Deposition.

\section{References}

[1] G. Garton, B. M. Wanklyn, Polymorphism in $\mathrm{Li}_{3} \mathrm{AlF}_{6}$, J. Inorg. Nucl. Chem 27 (1965) 2466-2469.

[2] G. Garton, B. M. Wanklyn, Some observations on the tetrafluoroaluminates of lithium and sodium, J. Inorg. Nucl. Chem. 27 1965) 2461-2465.

[3] J. L. Holm, Phase Transitions and Structure of Lithium Cryolite, Acta Chem. Scand. 20 (1966) $1167-1169$.

[4] P. D. Greene, P. Gross, C. Hayman, Heat of Formation and Transition Temperatures of Solid Lithium Hexafluoaluminate, Trans. Faraday Soc. 64 (1968) 633-636.

[5] J. H. Burns, A. C. Tennissen, G. D. Brunton, The Crystal Structure of $\alpha-\mathrm{Li}_{3} \mathrm{AlF}_{6}$, Acta Cryst. B 24 (1968) 225-230.

[6] J. L. Holm, B. Jenssen, A Note on the Polymorphy and Structure of $\mathrm{Li}_{3} \mathrm{AlF}_{6}$, Acta Chem. Scand. 23 (1969) $1065-1068$.

[7] A. K. Tyagi, J. Köhler, Preparation and Rietveld Refinement of the Structure of $\beta-\mathrm{Li}_{3} \mathrm{AlF}_{6}$, Mater. Res. Bull. 32 (1997) 1683-1689.

[8] T. Oi, K. Miyauchi, Amorphous Thin Film Ionic Conductors of mLiF · nAlF 3 , Mater. Res. Bull. 16 (1981) 1281-1289.

[9] T. Oi, Mater. Res. Bull. Ionic Conductivity of Amorphous $\mathrm{mLiFnMF}_{3}$ Thin Films ( $\mathrm{M}=\mathrm{Al}, \mathrm{Cr}, \mathrm{Sc}$ or $\mathrm{Al}+\mathrm{Sc}) 19$ (1984) 1343-1348. 
[10] T. Oi, Ionic Conductivity of LiF Thin Films Containing Di- or Trivalent Metal Fluorides, Mater. Res. Bull. 19 (1984) 451-457.

[11] R. Miyazaki, H. Maekawa, $\mathrm{Li}^{+}-$Ion Conduction of $\mathrm{Li}_{3} \mathrm{AlF}_{6}$ Mechanically Milled with LiCl, ECS Electrochem. Lett. 1 (2012) A87-A89.

[12] Y. Lee, D. M. Piper, A. S. Cavanagh, M. J. Young, S.-H. Lee, S. M. George, “Atomic Layer Deposition of Lithium Ion Conducting $\left(\mathrm{AlF}_{3}\right)(\mathrm{LiF})_{\mathrm{x}}$ Alloys Using Trimethylaluminum, Lithium Hexamethyldisilazide and Hydrogen Fluoride-Pyridine", $14^{\text {th }}$ International Conference on Atomic Layer Deposition 15.-18.6.2014, Kyoto, Japan.

[13] H. Xia, H. L. Wang, W. Xiao, M. O. Lai, L. Lu, Thin film Li electrolytes for all-solid-state micro-batteries, Int. J. Surf. Sci. Eng. 3 (2009) 23-43.

[14] M. Nisula, Y. Shindo, H. Koga, M. Karppinen, Atomic Layer Deposition of Lithium Phosphorus Oxynitride, Chem. Mater. 27 (2015) 6987-6993.

[15] J. Liu, M. N. Banis, X. Li, A. Lushington, M. Cai, R. Li, T.-K. Sham, X. Sun, Atomic Layer Deposition of Lithium Tantalate Solid-State Electrolytes, J. Phys. Chem. C 117 (2013) 20260-20267.

[16] V. A. Pustovarov, I. N. Ogorodnikov, S. I. Omelkov, M. S. Molokeev, A. V. Kozlov, L. I. Isaenko, Photoluminescence of monoclinic $\mathrm{Li}_{3} \mathrm{AlF}_{6}$ crystals under vacuum ultraviolet and soft $\mathrm{X}$-ray excitations, Opt. Mater. 49 (2015) 201-207.

[17] M. Ahrens, G. Scholz, M. Feist, E. Kemnitz, Application of an alkoxide sol-gel route for the preparation of complex fluorides of the $\mathrm{MAlF}_{4}(\mathrm{M}=\mathrm{K}, \mathrm{Cs}), \mathrm{M}_{3} \mathrm{AlF}_{6}(\mathrm{M}=\mathrm{Li}, \mathrm{Na}, \mathrm{K})$, and $\mathrm{Na}_{5} \mathrm{Al}_{3} \mathrm{~F}_{14}$ type, Solid State Sci. 8 (2006) 798-806.

[18] M. Leskelä, M. Ritala, Atomic Layer Deposition Chemistry: Recent Developments and Future Challenges, Angew. Chem. Int. Ed. 42 (2003) 5548-5554.

[19] J. Niinistö, K. Kukli, M. Heikkilä, M. Ritala, M. Leskelä, Atomic Layer Deposition of High-k Oxides of the Group 4 Metals for Memory Applications, Adv. Eng. Mater. 11 (2009) 223-234.

[20] S. D. Elliott, O. Nilsen, Reaction Mechanisms in ALD of Ternary Oxides, ECS Trans. 41 (2011) $175-183$.

[21] Y. Cao, X. Meng, J. W. Elam, Atomic Layer Deposition of $\mathrm{Li}_{\mathrm{x}} \mathrm{Al}_{\mathrm{y}} \mathrm{S}$ Solid-State Electrolytes for Stabilizing Lithium-Metal Anodes, ChemElectroChem 3 (2016) 858-863.

[22] M. Vehkamäki, T. Hatanpää, M. Ritala, M. Leskelä, S. Väyrynen, E. Rauhala, Atomic Layer Deposition of $\mathrm{BaTiO}_{3}$ Thin Films - Effect of Barium Hydroxide Formation, Chem. Vap. Deposition 13 (2007) 239-246.

[23] M. Putkonen, T. Aaltonen, M. Alnes, T. Sajavaara, O. Nilsen, H. Fjellvåg, Atomic Layer Deposition of Lithium Containing Thin Films. J. Mater. Chem. 19 (2009) 8767-8771. 
[24] O. Nilsen, V. Miikkulainen, K. B. Gandrud, E. Østreng, A. Ruud, H. Fjellvåg, Atomic layer deposition of functional films for Li-ion microbatteries, Phys. Status Solidi A 211 (2014) 357-367.

[25] X. Meng, X.-Q. Yang, X. Sun, Emerging Applications of Atomic Layer Deposition for LithiumIon Battery Studies, Adv. Mater. 24 (2012) 3589-3615.

[26] T. Aaltonen, O. Nilsen, A. Magrasó, H. Fjellvåg, Atomic Layer Deposition of $\mathrm{Li}_{2} \mathrm{O}-\mathrm{Al}_{2} \mathrm{O}_{3}$ Thin Films, Chem. Mater. 23 (2011) 4669-4675.

[27] M. Mäntymäki, J. Hämäläinen, E. Puukilainen, T. Sajavaara, M. Ritala, M. Leskelä, Atomic Layer Deposition of $\mathrm{LiF}$ Thin Films from Lithd, $\mathrm{Mg}(\text { thd })_{2}$, and $\mathrm{TiF}_{4}$ Precursors, Chem. Mater. 25 (2013) $1656-1663$.

[28] V. Miikkulainen, A. Ruud, E. Østreng, O. Nilsen, M. Laitinen, T. Sajavaara, H. Fjellvåg, Atomic Layer Deposition of Spinel Lithium Manganese Oxide by Film-Body-Controlled Lithium Incorporation for Thin-Film Lithium-Ion Batteries, J. Phys. Chem. C 118 (2014) 1258-1268.

[29] I. Stassen, M. Styles, G. Grenci, H. Van Gorp, W. Vanderlinden, S. De Feyter, P. Falcaro, D. De Vos, P. Vereecken, R. Ameloot, Chemical vapour deposition of zeolitic imidazolate framework thin films, Nat. Mater. 15 (2016) 304-310.

[30] M. Ylilammi, T. Ranta-aho, Metal Fluoride Thin Films Prepared by Atomic Layer Deposition, J. Electrochem. Soc. 141 (1994) 1278-1284.

[31] Y. Lee, J. W. Dumont, A. S. Cavanagh, S. M. George, Atomic Layer Deposition of $\mathrm{AlF}_{3}$ Using Trimethylaluminum and Hydrogen Fluoride, J. Phys. Chem. C 119 (2015) 14185-14194.

[32] Y. Lee, Atomic Layer Etching of Metal Oxides and Atomic Layer Deposition of Metal Fluorides, Doctoral Thesis, University of Colorado Boulder (2015).

[33] T. Pilvi, K. Arstila, M. Leskelä, M. Ritala, Novel ALD Process for Depositing $\mathrm{CaF}_{2}$ Thin Films, Chem. Mater. 19 (2007) 3387-3392.

[34] T. Pilvi, T. Hatanpää, E. Puukilainen, K. Arstila, M. Bischoff, U. Kaiser, N. Kaiser, M. Leskelä, M. Ritala, Study of a novel ALD process for depositing $\mathrm{MgF}_{2}$ thin films, J. Mater. Chem. 17 (2007) 5077-5083.

[35] T. Pilvi, E. Puukilainen, K. Arstila, M. Leskelä, M. Ritala, Atomic Layer Deposition of $\mathrm{LaF}_{3}$ Thin Films using $\mathrm{La}(\text { thd })_{3}$ and $\mathrm{TiF}_{4}$ as Precursors, Chem. Vap. Deposition 14 (2008) 85-91.

[36] T. Pilvi, E. Puukilainen, F. Munnik, M. Leskelä, M. Ritala, ALD of $\mathrm{YF}_{3}$ Thin Films from $\mathrm{TiF}_{4}$ and Y(thd) $)_{3}$ Precursors, Chem. Vap. Deposition 15 (2009) 27-32.

[37] T. Pilvi, E. Puukilainen, U. Kreissig, M. Leskelä, M. Ritala, Atomic Layer Deposition of $\mathrm{MgF}_{2}$ Thin Films Using $\mathrm{TaF}_{5}$ as a Novel Fluorine Source, Chem. Mater. 20 (2008) 5023-5028. 
[38] M. Mäntymäki, J. Hämäläinen, E. Puukilainen, F. Munnik, M. Ritala, M. Leskelä, Atomic Layer Deposition of LiF Thin Films from Lithd and $\mathrm{TiF}_{4}$ Precursors, Chem. Vap. Deposition 19 (2013) 111116.

[39] M. Mäntymäki, M. J. Heikkilä, E. Puukilainen, K. Mizohata, B. Marchand, J. Räisänen, M. Ritala, M. Leskelä, Atomic Layer Deposition of $\mathrm{AlF}_{3}$ Thin Films Using Halide Precursors, Chem. Mater. 27 (2015) 604-611.

[40] M. Ylilammi, T. Ranta-aho, Optical determination of the film thicknesses in multilayer thin film structures, Thin Solid Films 232 (1993) 56-62.

[41] J. Jokinen, J. Keinonen, P. Tikkanen, A. Kuronen, T. Ahlgren, K. Nordlund, Comparison of TOFERDA and Nuclear Resonance Reaction Techniques for Range Profile Measurements of keV Energy Implants, Nucl. Instr. and Meth. B 119 (1996) 533-542.

[42] C. Li, X. Guo, L. Gu, D. Samuelis, J. Maier, Ionic Space-Charge Depletion in Lithium Fluoride Thin Films on Sapphire (0001) Substrates, Adv. Funct. Mater. 21 (2011) 2901-2905.

[43] C. Li, L. Gu, J. Maier, Enhancement of the Li Conductivity in LiF by Introducing Glass/Crystal Interfaces, Adv. Funct. Mater. 22 (2012) 1145-1149.

[44] PDF 00-022-1137, JCPDS-ICDD, International Center for Diffraction Data.

[45] Inorganic Crystal Structure Database (ICSD), collection code 85171.

[46] E. Atosuo, M. Mäntymäki, K. Mizohata, M. J. Heikkilä, J. Räisänen, M. Ritala, M. Leskelä, Preparation of Lithium Containing Oxides by the Solid State Reaction of Atomic Layer Deposited Thin Films, Chem. Mater. 29 (2017) 998-1005. 


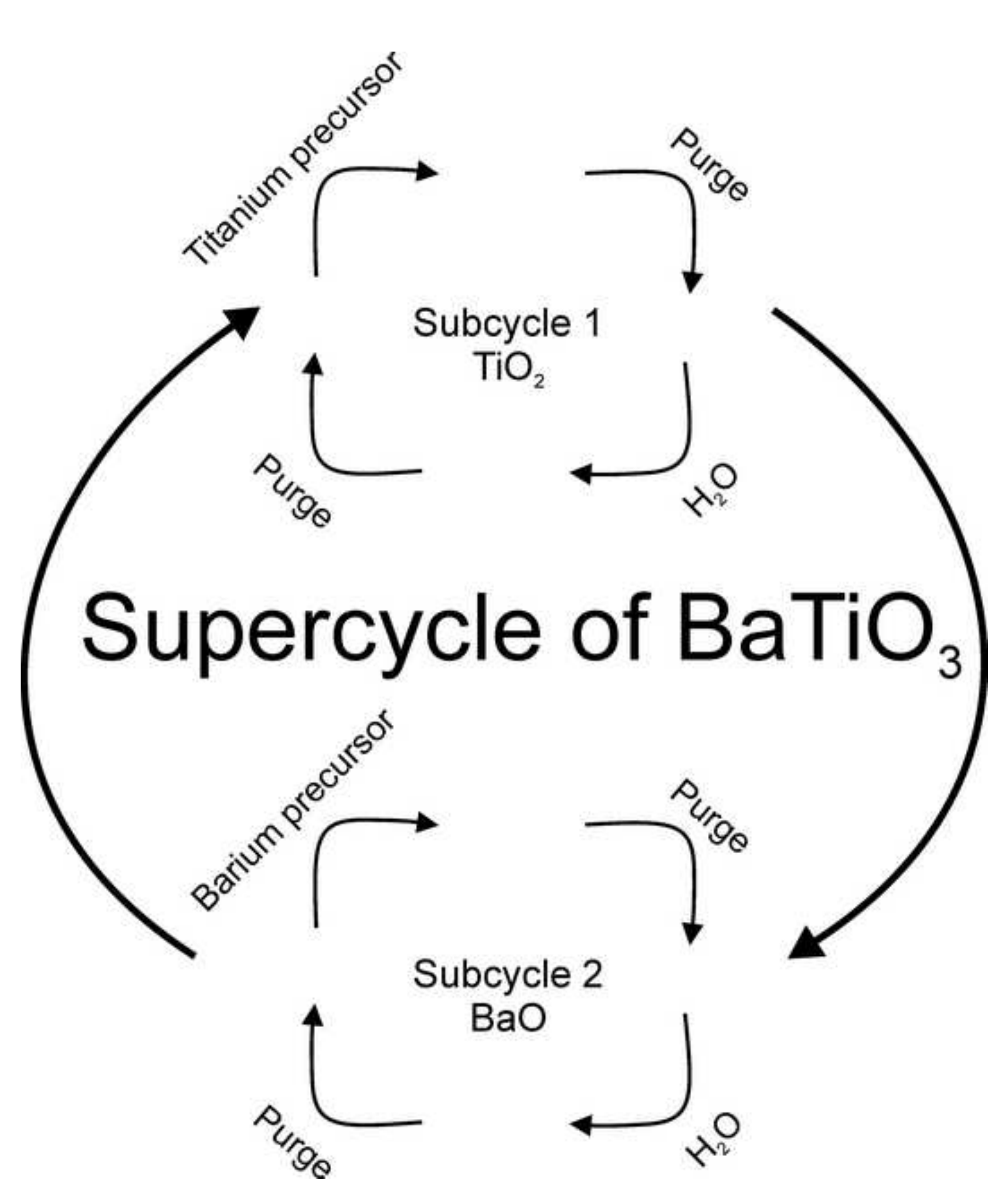

Scheme1 
Process 1
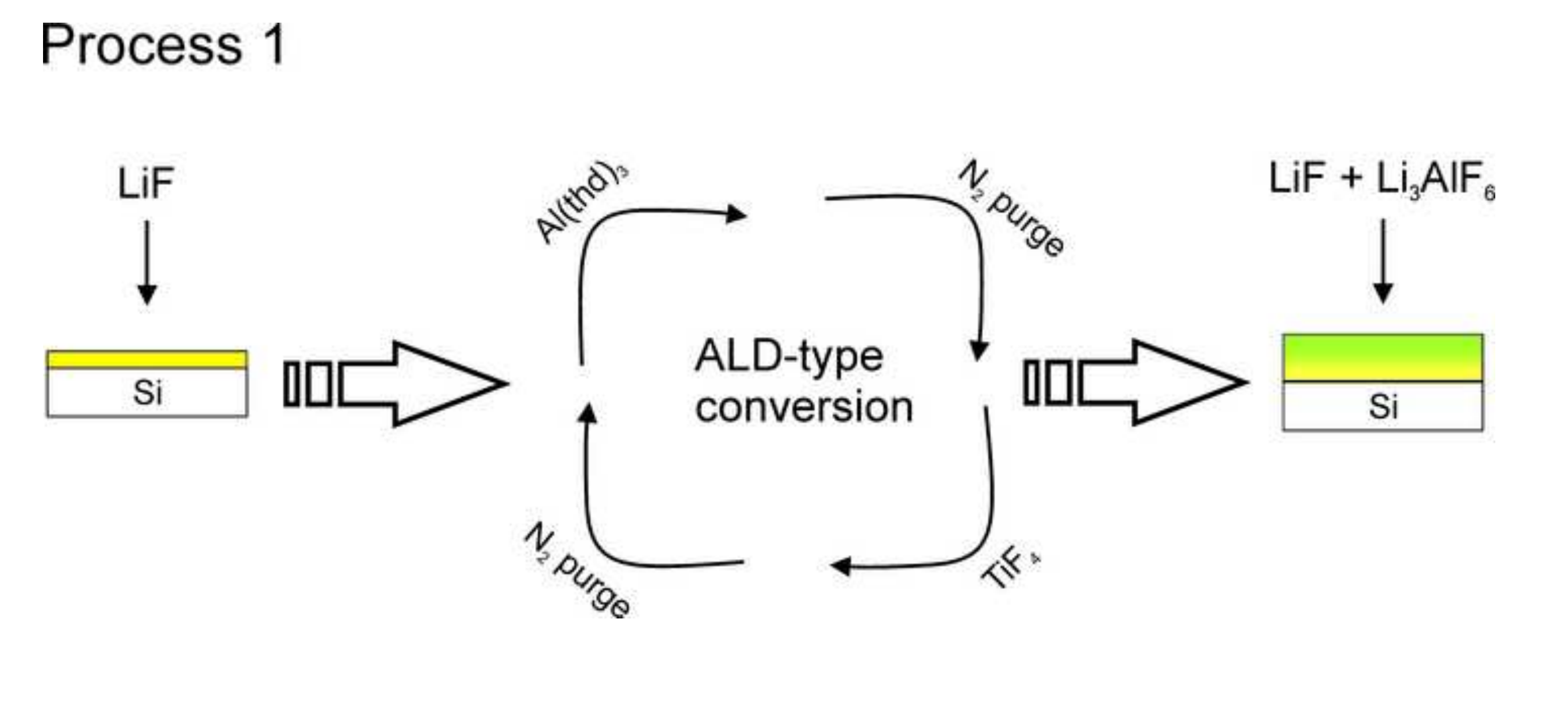

.

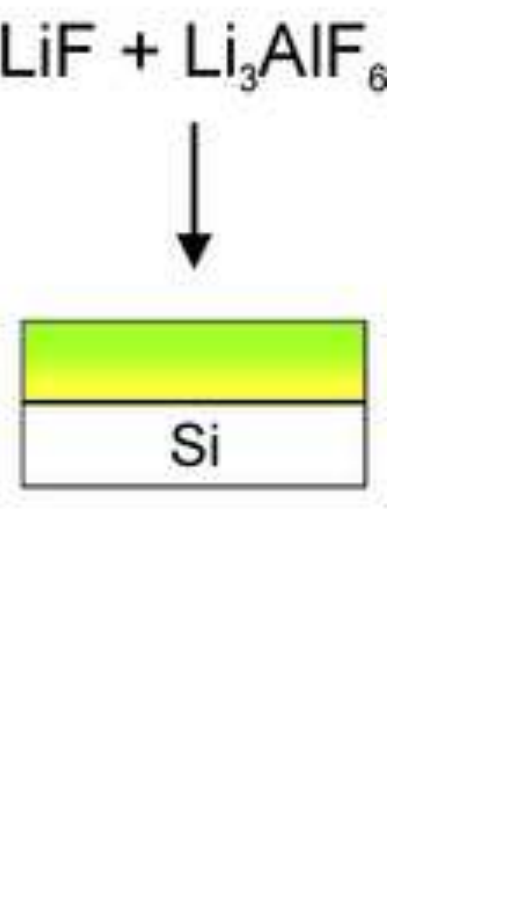




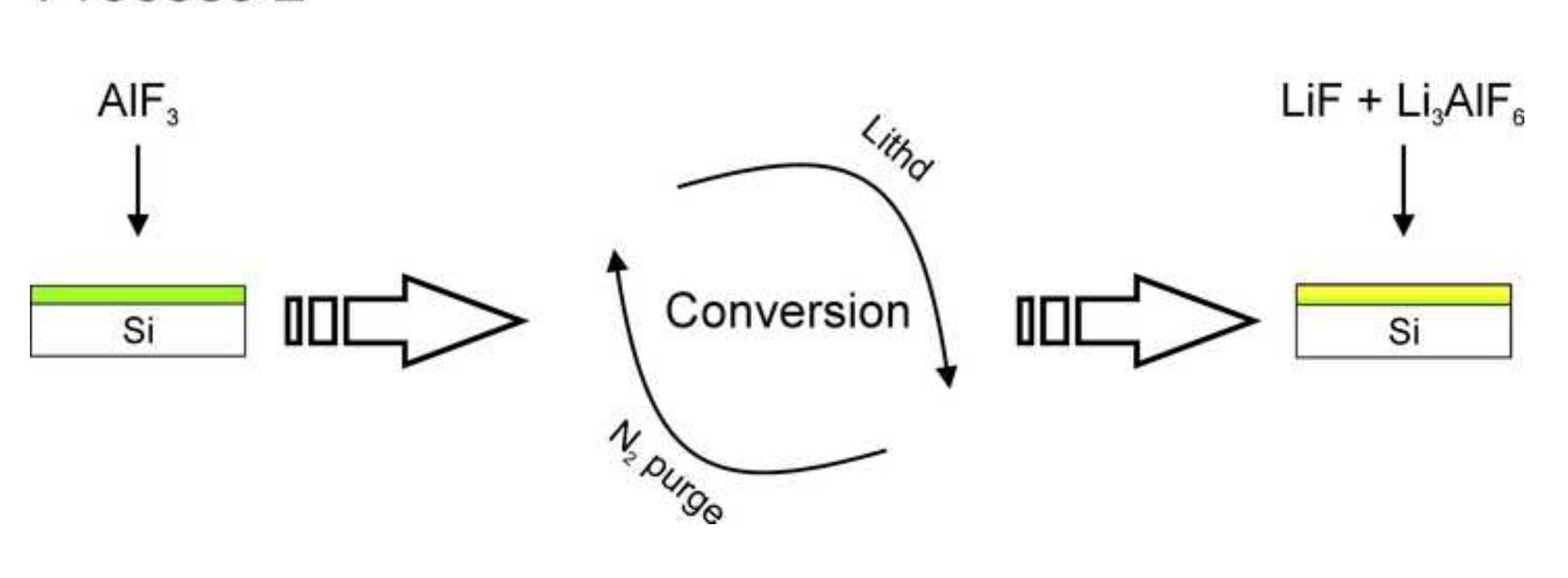

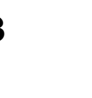

ra

\section{Process 2

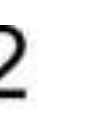

$$
\text { . }
$$




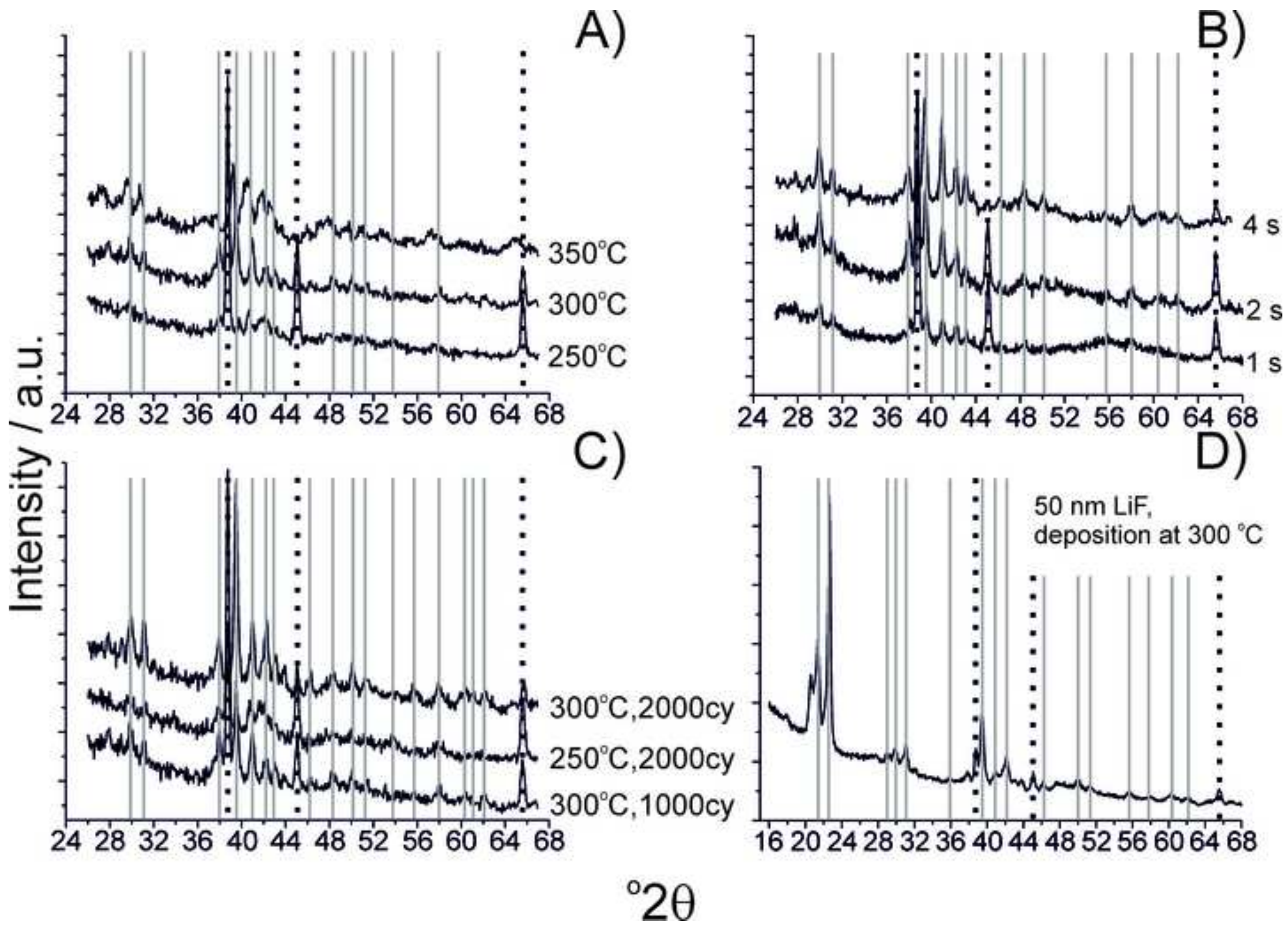




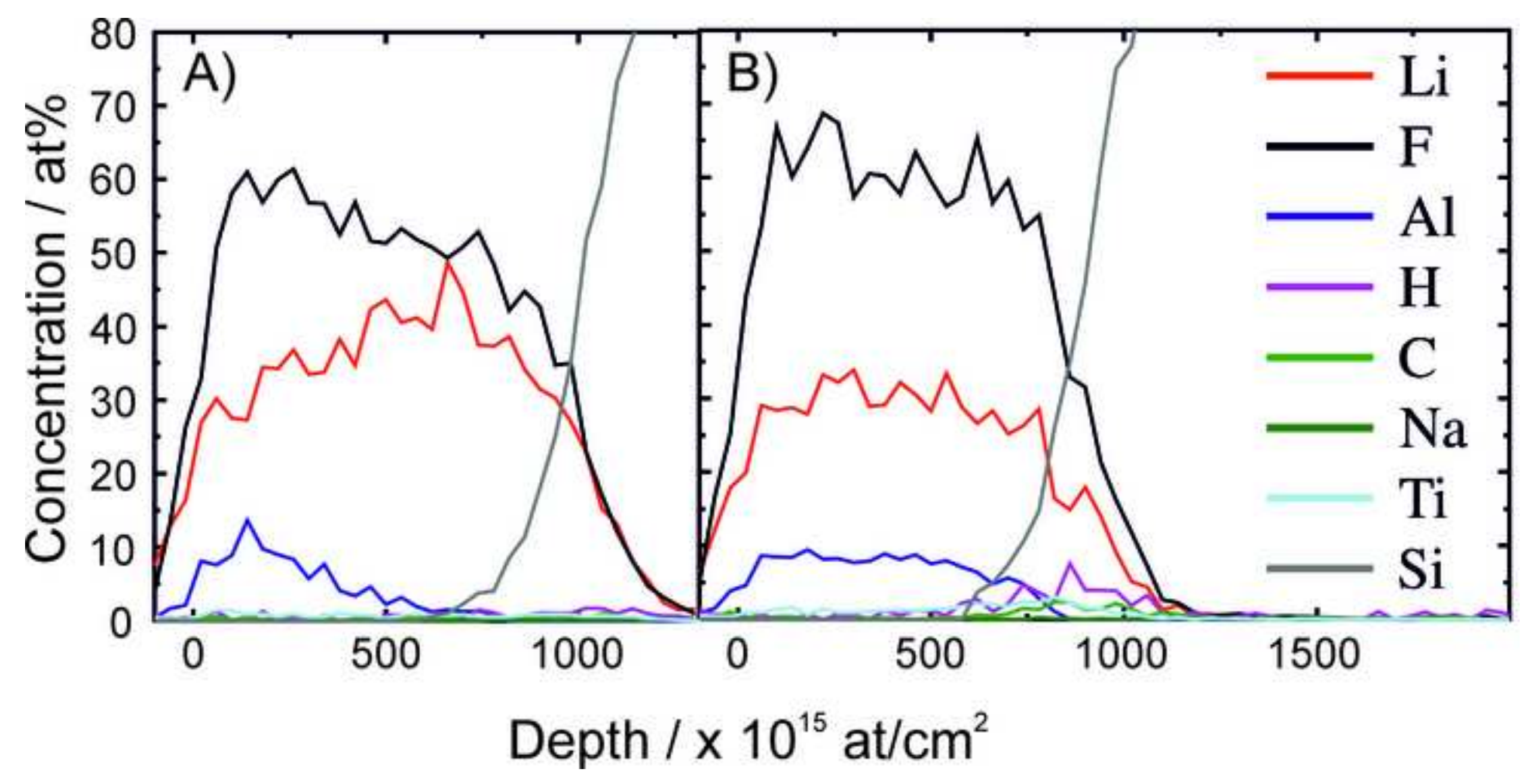




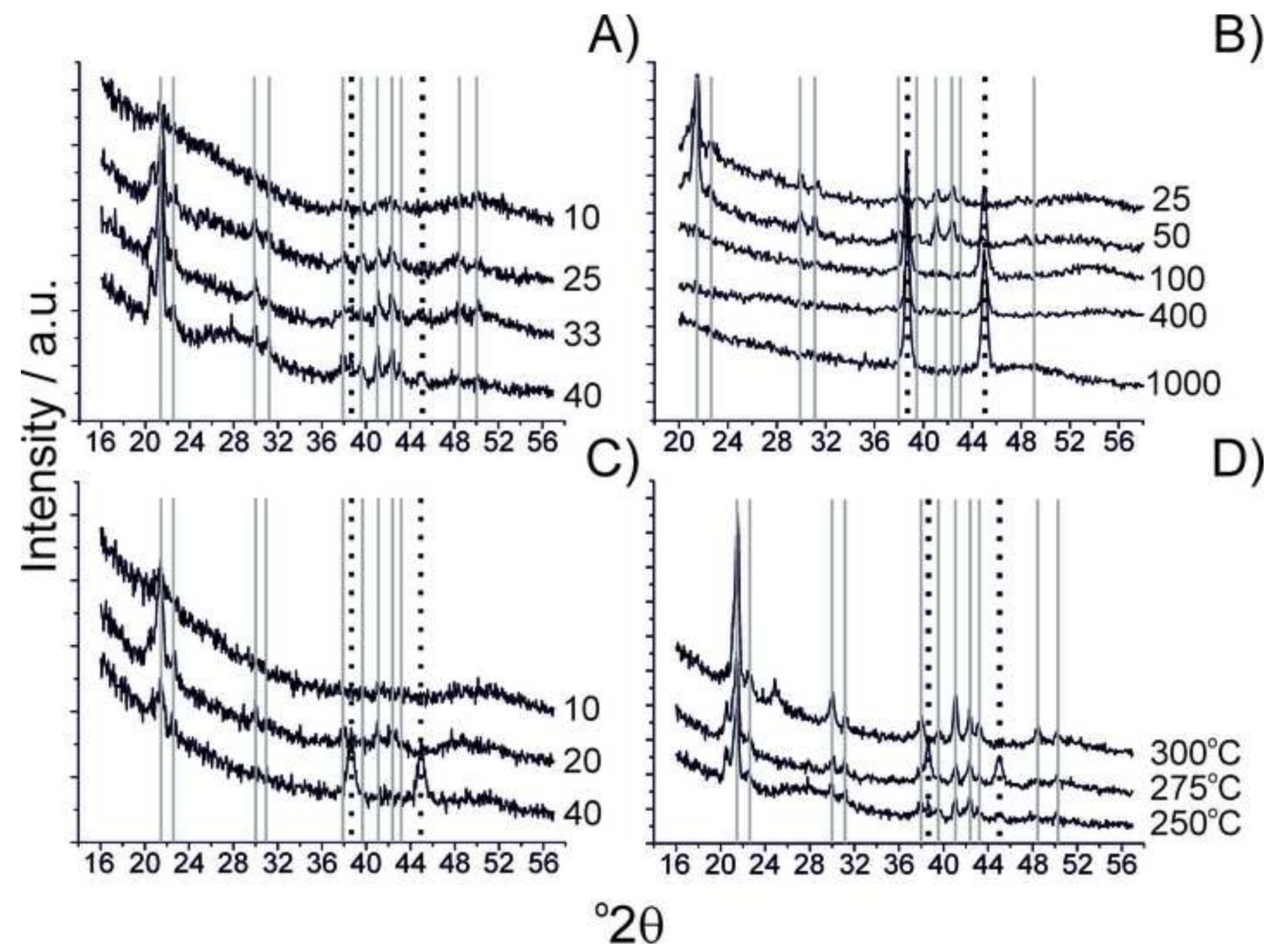




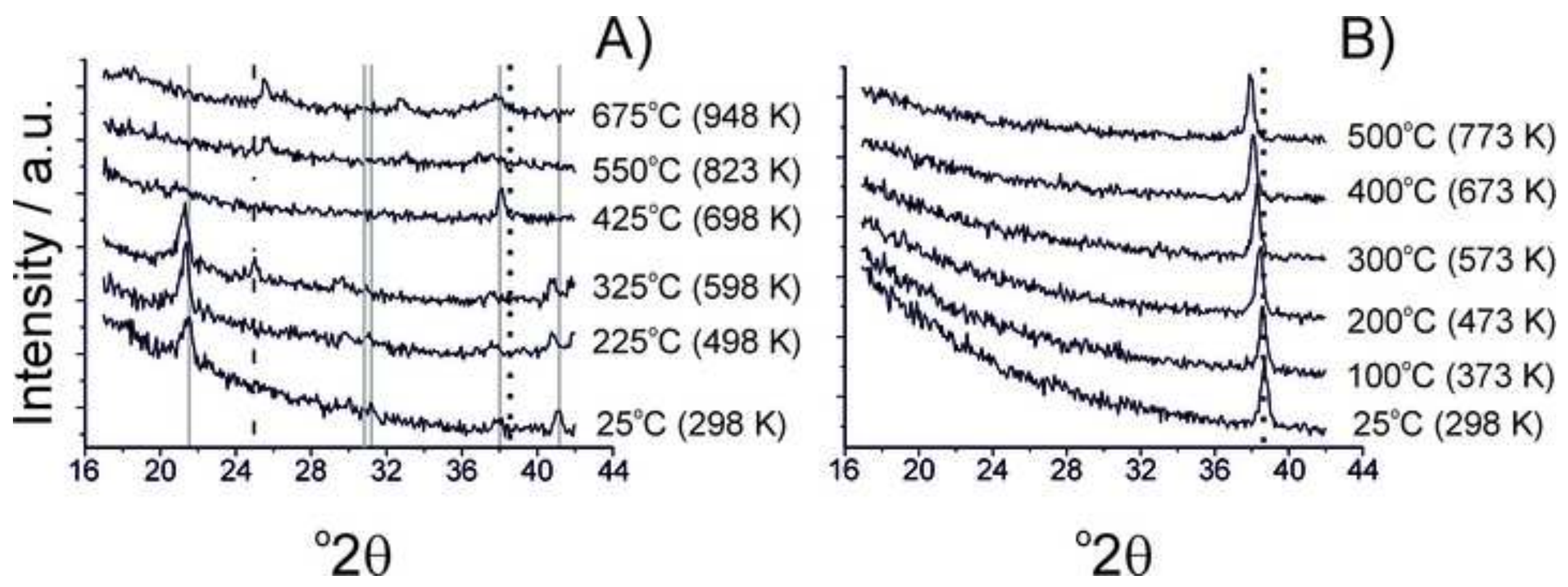




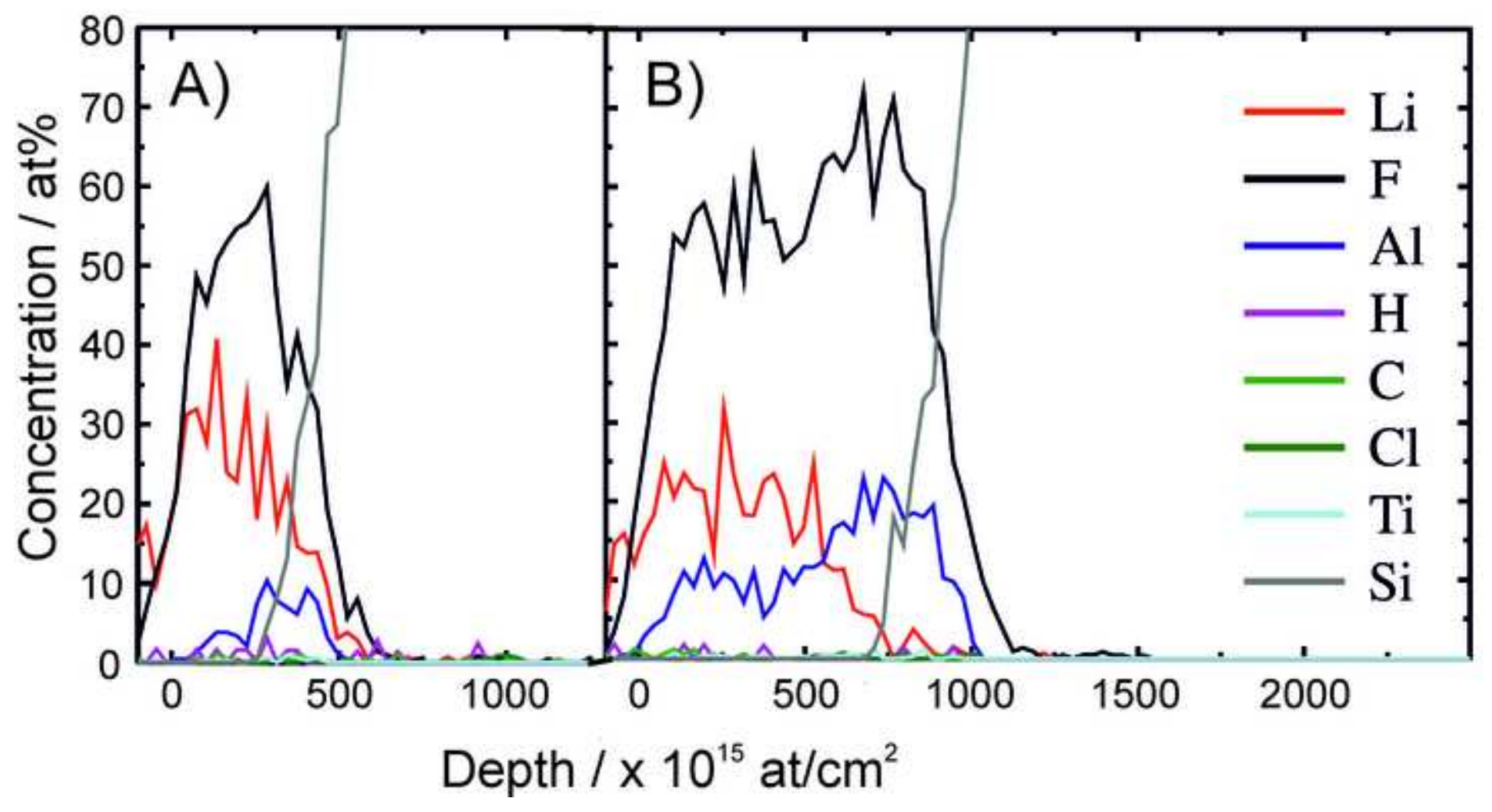




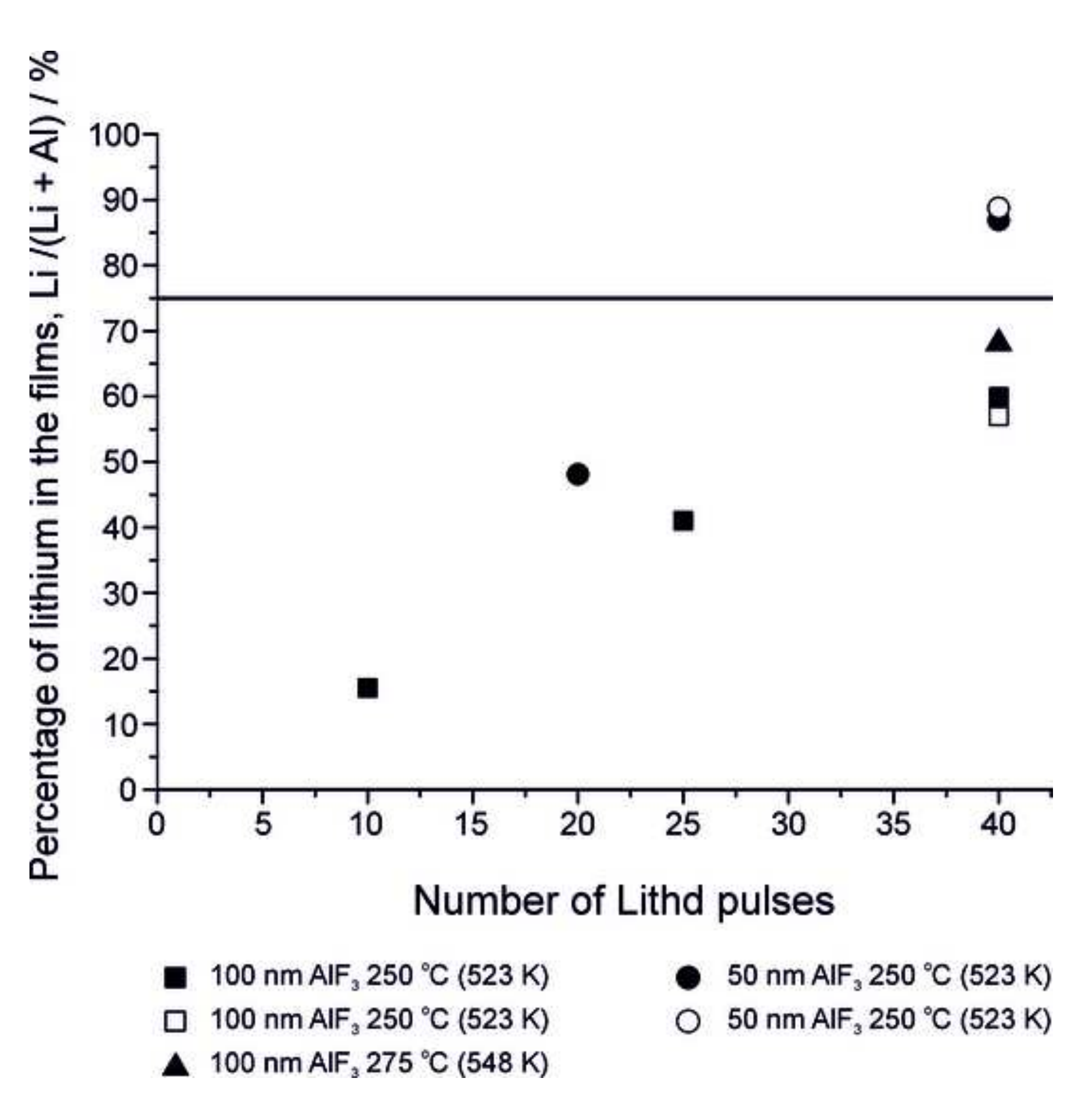

. A $100 \mathrm{~nm} \mathrm{AlF}_{3} 275^{\circ} \mathrm{C}(548 \mathrm{~K})$
- $50 \mathrm{nmAlF}_{3} 250^{\circ} \mathrm{C}(523 \mathrm{~K})$

.

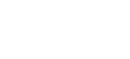
列

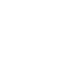
$\triangle 100$ mafr,

(1)

${ }^{\circ} \mathrm{C}(523 \mathrm{~K})$
${ }^{\circ} \mathrm{C}(523 \mathrm{~K})$
${ }^{\circ} \mathrm{C}(548 \mathrm{~K})$
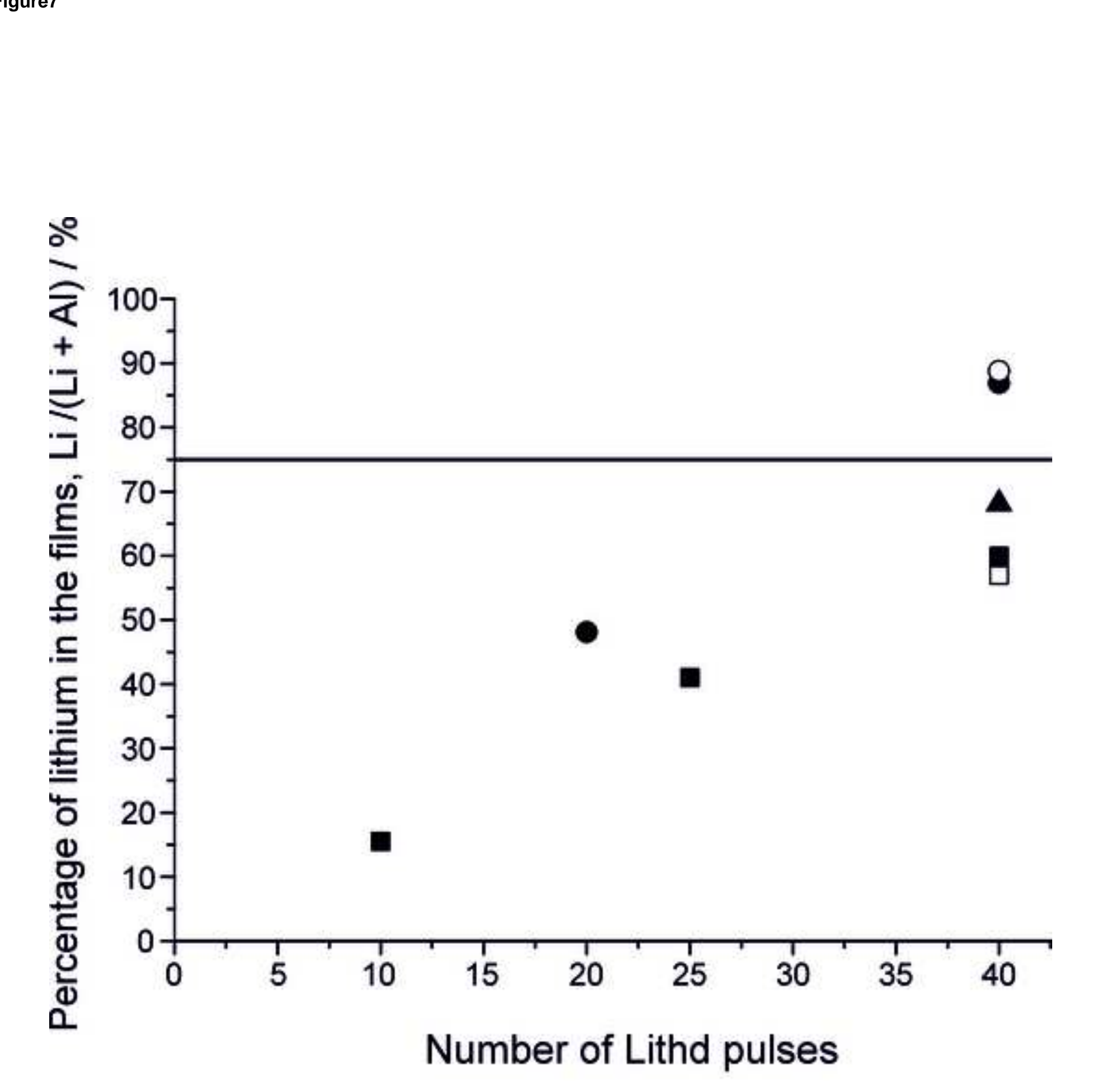

更




\section{A) $100 \mathrm{~nm}$}
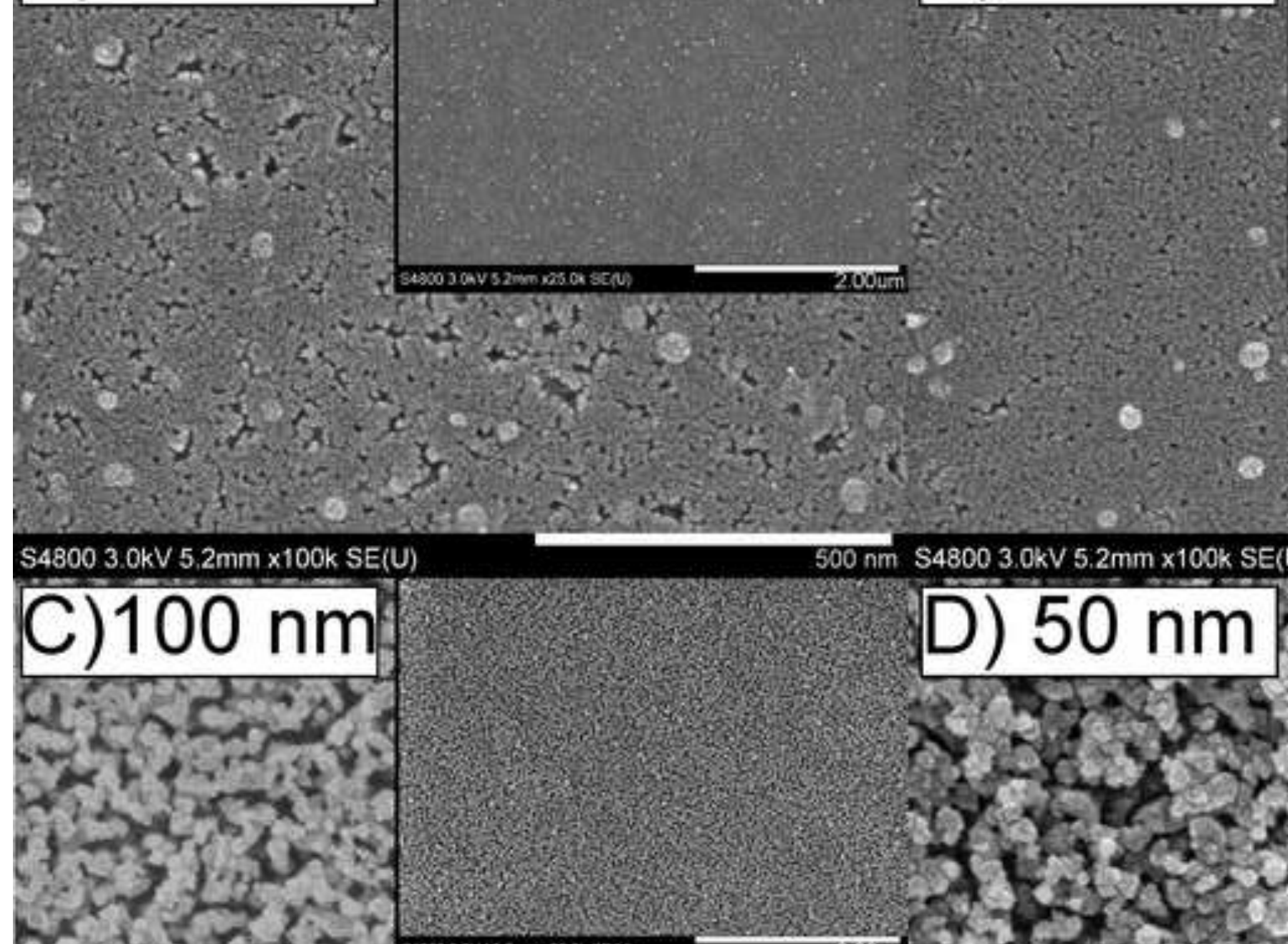

B) $50 \mathrm{~nm}$

(4)

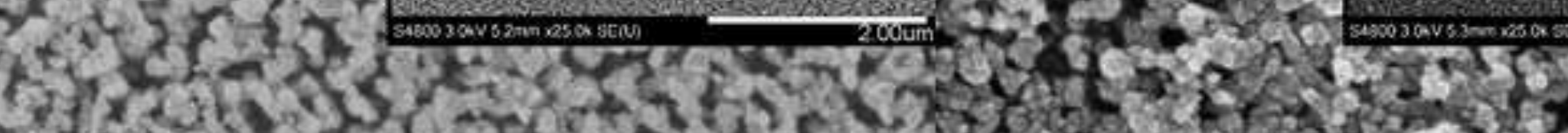

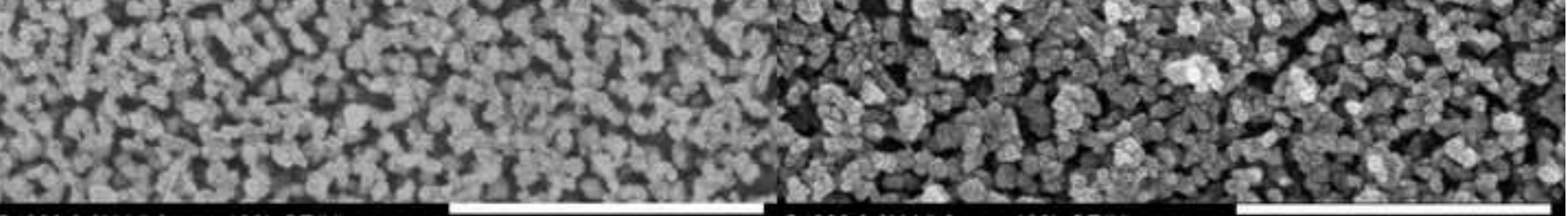


